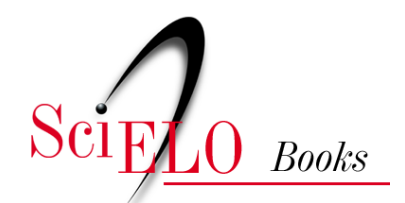

\title{
Capítulo 2 \\ Marco constitucional sobre la economía popular solidaria y el sector financiero popular solidario
}

\author{
Ana Castro Medina
}

\section{SciELO Books / SciELO Livros / SciELO Libros}

CASTRO MEDINA, A. Marco constitucional sobre la economía popular solidaria y el sector financiero popular solidário. In: Economía popular y solidaria: ¿realidad o utopía?. Caracterización de las entidades de fomento [online]. Quito: Editorial Abya-Yala, 2018, pp. 55-87. ISBN: 978-9978-10490-3. https://doi.org/10.7476/9789978104903.0003.

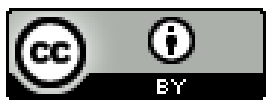

All the contents of this work, except where otherwise noted, is licensed under a Creative Commons Attribution 4.0 International license.

Todo o conteúdo deste trabalho, exceto quando houver ressalva, é publicado sob a licença Creative Commons Atribição 4.0.

Todo el contenido de esta obra, excepto donde se indique lo contrario, está bajo licencia de la licencia Creative Commons Reconocimento 4.0. 
Capítulo 2

\section{Marco constitucional sobre la economía popular solidaria y el sector financiero popular solidario}

La Constitución de 2008 marca un hito en la historia del país ya que, entre otros aspectos, establece como Régimen el "Buen Vivir" y declara además que su sistema económico será social y solidario. ¿Por qué es un hecho histórico?, a decir de algunos autores ${ }^{23}$ este hecho transciende porque no constituye una simple reforma, sus implicaciones pasan por la posibilidad de una refundación del Estado y la nación, es inédito porque proviene de "formas de vida" de sectores excluidos, se refieren a las indígenas y las afroecuatorianas. Alejarse de las tradiciones occidentales podría reflejar un deseo por abandonar una matriz desde la cual históricamente se han elaborado los discursos de modernidad en Ecuador. Acontecimiento de carácter político, que generó el debate e implementación de un nuevo marco normativo destinado a viabilizar otra economía (Cortez, 2013).

23 Sobre la construcción social del "Buen Vivir" (Sumak Kawsay) en Ecuador, se realiza una genealogía completa desde la lectura del: ambientalismo y desarrollo, marxismo y socialismo, teología de la liberación, proyecto político de la CONAIE 1997, el fondo indígena; y desde las matrices: indígena y afroecuatoriana, liberal y neoliberal, iglesia de los pobres, marxista y socialista, ambientalista, feminista (Cortez, 2013). 
En este acápite se revisara el marco legal y los principales artículos que definen y delimitan al Sector de la Economía Popular y Solidaria:

\section{Constitución de la República del Ecuador}

La Constitución de la República en su articulado establece un tratamiento específico y diferenciado del Estado para potenciar, fortalecer y desarrollar a la Economía Popular y Solidaria, a fin de que mantenga una relación dinámica y equilibrada con la Economía Pública y Privada (MIES-IEPS, 2011).

En el Artículo 283 prescribe:

El sistema económico es social y solidario; reconoce al ser humano como sujeto y fin; propende a una relación dinámica y equilibrada entre sociedad, Estado y mercado, en armonía con la naturaleza; y tiene por objetivo garantizar la producción y reproducción de las condiciones materiales e inmateriales que posibiliten el buen vivir.

El sistema económico se integrará por las formas de organización económica pública, privada, mixta, popular y solidaria, y las demás que la Constitución determine. La economía popular y solidaria se regulará de acuerdo con la ley e incluirá a los sectores cooperativistas, asociativos y comunitarios (Asamblea Constituyente, 2008).

El Artículo 288 determina que:

Las compras públicas cumplirán con criterios de eficiencia, transparencia, calidad, responsabilidad ambiental y social. Se priorizarán los productos y servicios nacionales, en particular los provenientes de la economía popular y solidaria, y de las micro, pequeñas y medianas unidades productivas (Asamblea Constituyente, 2008).

El Artículo 309, textualmente señala: "El sistema financiero nacional se compone de los sectores público, privado, y del popular y solidario que intermedian recursos del público. (...)” (Asamblea Constituyente, 2008). 
El Artículo 311 de la misma Constitución establece que:

El sector financiero popular y solidario se compondrá de cooperativas de ahorro y crédito, entidades asociativas o solidarias, cajas bancos comunales, cajas de ahorro. Las iniciativas de servicios del sector financiero popular y solidario, y de las micro, pequeñas y medianas unidades productivas, recibirán un tratamiento diferenciado y preferencial del Estado, en la medida que impulsen el desarrollo de la economía popular y solidaria (Asamblea Constituyente, 2008).

La Constitución en el Artículo 319 reconoce diversas formas de organización de la producción en la economía, entre otras las comunitarias, cooperativas, empresariales públicas o privadas, asociativas, familiares, domésticas, autónomas y mixtas.

\section{Plan Nacional para el Buen Vivir 2009-2013}

El Plan Nacional para el Buen Vivir 2009-2013 planteó nuevos retos orientados hacia la materialización y radicalización del proyecto de cambio, a la construcción de un Estado Plurinacionalidad e Intercultural y finalmente a alcanzar el Buen Vivir de las y los ecuatorianos, que finalmente se plasmaron en el nuevo pacto social que constituye la Constitución de la República del Ecuador (SENPLADES, 2009).

Algunas de las revoluciones que buscan concretarse en este Plan aluden a:

La Revolución económica, productiva y agraria, para superar el modelo de exclusión y orientar los recursos del Estado a la educación, salud, vialidad, vivienda, investigación científica y tecnológica, trabajo y reactivación productiva, en armonía y complementariedad entre zonas rurales y urbanas.

La Revolución social, para que a través de una política social articulada a una política económica incluyente y movilizadora, el Estado garantice los derechos fundamentales de todas las personas, comunidades, pueblos y nacionalidades. 
En su primera fase el Plan se planteó estrategias de cambio, entre ellas:

Democratización de los medios de producción, re-distribución de la riqueza y diversificación de las formas de propiedad y de organización. Esta estrategia tiene por objetivo general construir tres condiciones fundamentales para el Buen Vivir. La primera es la sostenibilidad económica a través de la canalización del ahorro a la inversión productiva, pública y privada, de manera eficiente. La segunda estrategia alude al desarrollo de capacidades humanas y oportunidades sociales, que hagan posible una organización económica más equitativa y una convivencia social más justa. Por último, la tercera estrategia se refiere a la acumulación de capital productivo necesario para cambiar el patrón de especialización de la economía y el modo de acumulación.

Entre sus objetivos constan:

- Auspiciar la igualdad, cohesión e integración social y territorial en la diversidad.

- Mejorar las capacidades y potencialidades de la ciudadanía.

- Mejorar la calidad de vida de la población.

- Afirmar y fortalecer la identidad nacional, las identidades diversas, la plurinacionalidad y la interculturalidad.

- Establecer un sistema económico social, solidario y sostenible.

El Objetivo 11: "Establecer un sistema económico social, solidario y sostenible" (SENPLADES, 2009).

Para este efecto la Constitución de 2008 establece que el sistema económico ecuatoriano es social y solidario (Asamblea Constituyente, 2008).

La acción del Estado no sólo como ente regulador de la economía sino como redistribuidor y protagonista directo de la actividad económica es una condición indispensable para la justicia económica 
y el tránsito hacia otro modelo. Se trata de acciones y procesos, tales como la desprivatización y el control público de recursos e infraestructura estratégicos y fundamentales, como sustento material de la vida y como fuente de riqueza social; la planificación de la economía endógena para el Buen Vivir; la inversión y las compras públicas, orientadas a crear condiciones productivas y a estimular a sectores y territorios en situación de desventaja; la ampliación y consolidación de empresas y servicios públicos; y el impulso de una integración regional y económica e condiciones beneficiosas para el país.

La nueva matriz productiva establece directa relación con las transformaciones en el terreno de las tecnologías y conocimientos, concebidos como bienes públicos y en perspectiva de diversidad. Se asocia, también, con un sector financiero que articule el sector público, privado y popular solidario, cuyo control y orientación, en calidad de servicio público, es indispensable para encauzar el ahorro nacional hacia la producción en sus diversas formas.

Como políticas se plantea:

1. Impulsar una economía endógena para el Buen Vivir, sostenible y territorialmente equilibrada, que propenda a la garantía de derechos y a la transformación, diversificación y especialización productiva a partir del fomento a las diversas formas de producción.

2. Impulsar la actividad de pequeñas y medianas unidades económicas asociativas y fomentar la demanda de los bienes y servicios que generan.

3. Impulsar las condiciones productivas necesarias para el logro de la soberanía alimentaria.

4. Impulsar el desarrollo soberano de los sectores estratégicos en el marco de un aprovechamiento ambiental y socialmente responsable de los recursos no renovables. 
5. Fortalecer y ampliar la cobertura de infraestructura básica y de servicios públicos para extender las capacidades y oportunidades económicas.

6. Diversificar los mecanismos para los intercambios económicos, promover esquemas justos de precios y calidad para minimizar las distorsiones de la intermediación, y privilegiar la complementariedad y la solidaridad.

7. Promover condiciones adecuadas para el comercio interno e internacional, considerando especialmente sus interrelaciones con la producción y con las condiciones de vida.

8. Identificar, controlar y sancionar las prácticas de competencia desleales, y toda violación a los derechos económicos y a los bienes públicos y colectivos para fomentar la igualdad de condiciones y oportunidades en los mercados.

9. Promover el acceso a conocimientos y tecnologías y a su generación endógena como bienes públicos.

10. Promover cambios en los patrones de consumo, a fin de reducir su componente importado y suntuario, generalizar hábitos saludables y prácticas solidarias, social y ambientalmente responsables.

11. Promover la sostenibilidad ecosistémica de la economía a través la implementación de tecnologías y prácticas de producción limpia.

12. Propender hacia la sostenibilidad macroeconómica fortaleciendo al sector público en sus funciones económicas de planificación, redistribución, regulación y control.

13. Promover el ahorro y la inversión nacionales, consolidando el sistema financiero como servicio de orden público, con un adecuado funcionamiento y complementariedad entre sector público, privado y popular solidario. (SENPLADES, 2009). 


\section{Agenda de Política Económica para el Buen Vivir (Ministerio de Coordinación de la Política Económica, 2011)}

La elaboración e implementación de la Agenda de Política Económica para el Buen Vivir 2011-2013 es responsabilidad del Consejo Sectorial de Política Económica, que tiene su ente articulador en el Ministerio de Coordinación de la Política Económica (MCPE).

Este Consejo está conformado por doce entidades gubernamentales y le corresponde establecer y aplicar políticas y regulaciones a los flujos macroeconómicos para lograr el máximo nivel de producción y utilización de las capacidades instaladas en los recursos de la producción; garantizando al mismo tiempo su sostenibilidad intertemporal en el marco de la Constitución, y en concordancia con los objetivos del Plan Nacional del Buen Vivir. Los ámbitos de acción y las instituciones del Ejecutivo se organizan dentro de la tradicional división de cuatro sectores de la economía: fiscal, financiero, externo y real.

Principales articulaciones: Relación con la transformación productiva y las finanzas populares en el país.

El Ministerio de Coordinación de la Política Económica y sus respectivas entidades coordinadas, tienen la responsabilidad de la administración de los flujos macroeconómicos que garanticen la canalización del ahorro hacia la inversión productiva, en el marco de las limitaciones que marca la dolarización, de los recursos del sector público y de las regulaciones que pueda emitir para evitar problemas de liquidez ante eventuales desmonetizaciones de la economía o de expansiones monetarias no deseadas. En esta línea se generan las condiciones y opciones de financiamiento que requieren el conjunto de políticas y programas destinados a potenciar la producción, el empleo y la competitividad en el país. Estos están enmarcados en las estrategias productivas de largo plazo definidas en el Plan Nacional para el Buen Vivir. La implementación específica de la transformación productiva 
le corresponde al Ministerio de Coordinación de la Producción, Empleo y Competitividad y su respectivo consejo sectorial.

De igual manera, el impulso a las finanzas populares y su adecuado financiamiento, son parte de la política del Ministerio. En Desarrollo Social, que es el responsable institucional para consolida el sector de las finanzas populares a través de organizar, normar y potenciar el trabajo de cooperativas de ahorro y crédito cajas de ahorro y demás actores que comprenden este segmento de la economía nacional.

Dentro de las Políticas Económicas para el Buen Vivir, los grandes lineamientos de política que se desarrollarán como objetivos y estrategias en esta Agenda, son los siguientes:

- El sistema financiero debe constituirse en un apoyo efectivo para el aparato productivo y abandonar su estrategia marginalista. Este cambio de objetivo requiere una nueva arquitectura institucional, en la que los servicios financieros operen como servicios de orden público, fomenten la democratización del capital; canalicen el ahorro para el desarrollo de las actividades productivas con énfasis en los micro, pequeños y medianos empresarios.

- La política fiscal debe procurar la redistribución y equidad para ampliar las capacidades de todas y todos, y para crear los incentivos necesarios para garantizar el desarrollo y la consolidación de la soberanía alimentaria, energética y financiera.

La razón de ser del sistema financiero debe ser la transferencia de los recursos excedentarios a aquellos sectores del aparato productivo demandantes de crédito, no un instrumento de acumulación y concentración de la riqueza. Para ello, desde la óptica del Buen Vivir y en atención a los preceptos de la Constitución de la República, es necesario aplicar una modificación de carácter institucional para que la actividad financiera — cumpliendo con su función de servicio 
de orden público (El artículo 308 de la Constitución de la República establece la naturaleza y características básicas de las actividades financieras) promueva la democratización del capital y encamine el ahorro hacia las actividades productivas, especialmente las concernientes a los micro, pequeños y medianos empresarios. En este sentido, el sistema financiero debe ser una herramienta para apuntalar las transformaciones estructurales de la matriz productiva.

Las finanzas populares están llamadas a profundizar la intermediación y ampliación de la red financiera, garantizando el acceso al crédito a los actores de la Economía Popular y Solidaria, muchas veces excluidos de los circuitos tradicionales o formales de la producción y del consumo. El papel del sector financiero público debe justamente asegurar esta integración y recuperar sus facultades para fomentar la producción y la inversión, concentrando el ahorro interno para impulsar sistemas productivos alternativos y, sobre todo, procurando el cambio de la matriz productiva.

En el sector financiero, se han establecido los siguientes objetivos y estrategias:

- Democratizar el acceso al sistema financiero potenciando las finanzas populares y solidarias.

- Impulsar el acceso de los actores del Sector financiero popular y solidario al Sistema Nacional de Pagos (SNP)

La interconexión de entidades del sistema financiero popular y solidario con el SNP abrirá la posibilidad de ofrecer productos y servicios financieros en beneficio de los clientes atendidos por estas entidades financieras; como por ejemplo la entrega de microcréditos, la ampliación del pago del Bono de Desarrollo Humano, etc. Además, un SNP es un requisito para potenciar la desmaterialización del mismo. 
Para potenciar el SNP se han definido las siguientes estrategias:

a. Elaborar e implementar planes de integración de procesos informáticos entre las entidades financieras y el SNP.

b. Ampliar la oferta y calidad de los servicios financieros para las entidades financieras que participen en el SNP, facilitando el uso de sistemas y herramientas del propio SNP y del Banco Central del Ecuador.

c. Establecer sistemas de información y bases de datos que consoliden todas las transacciones efectuadas a través del SNP.

- Impulsar los procesos de inclusión financiera

La banca privada ha concentrado sus operaciones en provincias económicamente más importantes. El 72,5\% de la intermediación financiera de la banca privada se encuentra en las provincias de Pichincha y Guayas. Mientras tanto, los actores del segmento de Economía Popular y Solidaria que operan en buena medida en muchas otras provincias del país, financian sus actividades al margen de los circuitos financieros tradicionales. A diferencia de la concentración de cartera de la banca en Guayas y Pichincha, las cooperativas de ahorro y crédito apenas concentraron en estas provincias el 25,5\%.

Esta realidad genera muchas oportunidades. El impulso al segmento de finanzas populares y solidarias, además de contribuir a una mayor inclusión financiera, también favorece que una amplia gama de proyectos productivos no queden truncos por falta de acceso a servicios.

Las estrategias para profundizar la inclusión financiera en mayores segmentos de la población son:

a. Definir y aplicar un esquema de incentivos económicos y financieros preferenciales alineados al desarrollo de proyectos productivos prioritarios para la transformación de 
la matriz productiva del país y para iniciativas de inclusión financiera de grupos tradicionalmente excluidos.

b. Articular la infraestructura financiera de la banca pública con la de las entidades financieras populares y solidarias para lograr mayor cobertura de este sector y desconcentración de recursos financieros en las provincias más grandes.

c. Fortalecer la Corporación Nacional de Finanzas Populares y Solidarias y abrir líneas de crédito para el desarrollo de la Economía Popular y Solidaria.

d. Evaluar e implementar la construcción de esquemas de microseguros complementarios y de carácter sectorial, así como fortalecer el sistema de seguros procurando garantizar su salud y solvencia.

e. Impulsar la regulación de la reinversión territorial de la liquidez.

f. Implementar un producto financiero alternativo que desplace a los servicios prestados bajo prácticas ilegales de financiamiento.

- Canalizar el ahorro interno hacia la inversión productiva.

- Fomentar el ahorro de largo plazo y canalizarlo hacia la inversión productiva mediante el desarrollo del Mercado de Valores.

- Incrementar la eficiencia de la banca pública, la integralidad de las finanzas populares y solidarias; y la solidez del sistema financiero.

- Potenciar la banca pública para apoyar la transformación de la matriz productiva del país.

La banca pública tiene un rol fundamental dentro de la nueva arquitectura financiera que el país requiere para apuntalar el proceso de transformación de la matriz productiva. 
La nueva banca de desarrollo integrada trabajará de la siguiente manera:

a. Asignar segmentos de crédito especializados y enfocados en atender a los sectores prioritarios para la trasformación de la matriz productiva, evitando así una duplicidad de funciones y la competencia en un mismo mercado objetivo entre instituciones que son parte de la banca pública.

b. Fomentar la especialización de la banca pública mediante un adecuado control y supervisión de la cartera crediticia, por lo que se propone una reforma en la normatividad que permita la segmentación del crédito, con la correspondiente subdivisión según los productos que ofrecen las diferentes entidades públicas de desarrollo nacionales, según su naturaleza y las políticas públicas del gobierno.

c. Adecuar e integrar la infraestructura tecnológica para incrementar las capacidades de la banca pública para llegar a las zonas tradicionalmente excluidas, sin perder de vista la visión de rentabilidad financiera y social, y la sustentabilidad en el largo plazo.

d. Aplicar mecanismos de supervisión diferenciada en función de la nueva definición de funciones, objetivos y mercados para cada institución.

e. Incorporar principios y normas de Gobierno Corporativo para garantizar la gestión eficiente de las instituciones de la banca de desarrollo integrada.

f. Mejorar y fortalecer la administración y recuperación del crédito de la banca pública.

g. Impulsar el financiamiento de la oferta y demanda de vivienda de interés social

h. Impulsar el financiamiento del acceso a la educación a través de crédito. 
- Consolidar la institucionalidad del sistema financiero popular y solidario

La nueva Constitución de la República del Ecuador, vigente desde 2008, define el sistema económico del país como social y solidario (Asamblea Constituyente, 2008). Esto implica una ruptura con la visión centrada en el mercado que privilegiaba el capital por encima de los seres humanos. La anterior visión relegó a un segundo plano a una serie de actores que ahora constituyen el eje fundamental en la concepción económica del país: cooperativas de ahorro y crédito, cajas de ahorro y bancos comunales. A pesar de haber sido rezagados ante la mirada oficial, ellos han reforzado la economía del país, generado trabajo, soberanía alimentaria, etc. Actualmente, estos actores conforman el Sistema Financiero Popular y Solidario, el que requiere de una adecuada normativa y mecanismos de articulación con el sistema financiero nacional, sin perder de vista su naturaleza y características particulares (Artículos 309 y 311 de la Constitución del Ecuador y al Art.125 del Proyecto de Ley de la Economía Popular y Solidaria y del sector financiero popular y solidario) (Asamblea Constituyente, 2008) (Presidencia de la República, 2011). La institucionalidad para el sector, al igual que las obligaciones y derechos de los actores que lo conforman están establecidos en la Ley Orgánica de la Economía Popular y Solidaria y del Sector Financiero Popular y Solidario.

Desde la visión y competencias del ente rector de la política económica, se deben concretar una serie de estrategias para fortalecer a las entidades del Sistema Financiero Popular y Solidario y apoyar la gestión del Ministerio de Coordinación de Desarrollo para este sector:

a. Fortalecer las instituciones creadas para la supervisión y rectoría de este sector.

b. Mejorar el esquema de garantías a disposición del sector financiero social y solidario, de manera que le permita ampliar el acceso al crédito para los actores que han esta- 
do tradicionalmente al margen de los circuitos financieros regulares.

c. Adoptar nuevas tecnologías en los procesos de las entidades de las finanzas populares.

d. Establecer instrumentos de Buen Gobierno y control social de las entidades del sistema financiero, para fortalecerlas en lo técnico y para evitar prácticas que se contrapongan al espíritu social y solidario del sector.

Es fundamental consolidar un sistema financiero estable al largo plazo y fuerte, basado en adecuados indicadores de liquidez, solvencia y calidad de activos. En términos de control esto requiere apuntalar la Red de Seguridad Financiera y mejorar en lo relativo a prevenir riesgos sistémicos y enfrentar eventuales quiebras con el menor costo social posible, fortalecer la supervisión y control para atender oportuna y eficientemente problemas de liquidez y solvencia que presenten las Instituciones Financieras; e incrementar el nivel de confianza de los depositantes, en el sistema.

Es por ello, en términos de política financiera, se requiere:

a. Consolidar un sistema financiero sólido y sostenible en el largo plazo evitando prácticas oligopólicas. Se requiere fortalecer de manera importante de modo paulatino los requerimientos de capital de las entidades de crédito y mantener un colchón de conservación patrimonial para evitar la afectación de la procíclicidad propia de la actividad financiera en la economía.

b. Preservar la liquidez introduciendo un nuevo coeficiente de apalancamiento y exigencias generales mínimas por riesgo de liquidez, para que las entidades de crédito soporten situaciones de tensión de liquidez a corto plazo y aseguren la estabilidad a largo plazo de sus necesidades de financiamiento. 
c. Establecer un nivel de regulación y supervisión acorde con los riesgos que plantean para el sistema financiero y la economía real, aquellas entidades sistémicamente importantes.

d. Impulsar reformas normativas para complementar la Red de Seguridad Financiera, partiendo, entre otras cosas, de un adecuado entendimiento de la estructura del mercado ecuatoriano y del análisis crítico de mejores prácticas internacionales al respecto.

e. Mejorar la coordinación entre los entes de regulación del sistema financiero y establecer una estrecha colaboración con los reguladores de los países en los que los bancos ecuatorianos tienen oficinas, especialmente para compartir información.

f. Establecer mecanismos que permitan controlar la especulación inmobiliaria de activos fijos así como el sobre endeudamiento de las familias y los individuos.

g. Regular los fondos de inversión de alto riesgo o los fondos de capital de riesgo, introduciendo una serie de obligaciones para los gestores: registro, requisitos mínimos de capital e información.

h. Implementar una política de supervisión basada en riesgos, de una manera completa a nivel nacional, a todos los tipos de entidades que conforman el Sistema Financiero Nacional, sin dejar a un lado a los Sistemas de Seguro Privado, al Sistema de Seguridad Social y al Sistema Financiero Popular y Solidario, desde una óptica de supervisión diferenciada y especializada de cada caso.

i. Establecer mecanismos de alerta y respuesta temprana que permitan identificar posibles vulnerabilidades y aplicar oportunamente los correctivos necesarios a fin de aumentar la eficiencia de la supervisión y contar con una mejor 
evaluación de la situación económico-financiera actual y futura de las IFI.

- Desarrollar herramientas alternativas para el manejo de los flujos monetarios e instrumentos complementarios de liquidez

- Profundizar la desmaterialización del sistema nacional de pagos

Es necesario desarrollar instrumentos que faciliten los procesos de transferencia de dinero entre agentes financieros y no financieros, que permitan a la autoridad económica contar con un mejor control de los flujos monetarios que circulan en la economía ecuatoriana. Además, el uso de dólar físico genera costos de transacción mayores, en relación con operaciones que pueden ser desarrolladas de manera electrónica. Finalmente, el uso de medios electrónicos contribuye a elevar la eficiencia en la gestión de los sujetos financieros.

Las estrategias establecidas para ir un paso más allá en la desmaterialización y potenciamiento del Sistema de Pagos son:

a. Facilitar el acceso de la población a medios de pago electrónicos

b. Regular el Sistema de Pagos Móviles e impulsar su utilización.

c. Establecer medidas anti-monopólicas en el control de los medios de pago electrónico y redes transaccionales.

d. Establecer los mecanismos legales para desmaterializar una mayor cantidad de títulos valores.

e. Democratizar e impulsar el Sistema Nacional de Pagos.

\section{Agenda de la Revolución de la Economía Popular Solidaria}

La Ministra de Inclusión Económica y Social define la Agenda de la Revolución de la Economía Popular y Solidaria como una herramienta pragmática de política pública que busca consolidar, 
fortalecer, potenciar, promocionar y dinamizar tanto a los actores de la economía popular como a los actores de la economía popular y solidaria e impulsar la creación de condiciones objetivas para que éstos puedan interactuar de forma dinámica y equilibrada con los sectores privado y públicos; y, así desplegar la construcción del sistema económico social y solidario (IEPS, 2013).

El objetivo de la Agenda de la Revolución de la Economía Popular y Solidaria (AREPS), es generar una política central que cree las condiciones adecuadas para coaligar las capacidades de trabajo y los recursos de los actores de la Economía Popular y la Economía Popular y Solidaria a través de estrategias, políticas, programas y proyectos para organizar los procesos de producción, distribución, circulación y consumo dentro de una malla de relaciones de cooperación de las diferentes formas del trabajo entre sí y con la naturaleza.

La AREPS es el resultado de la co-construcción, deliberación, participación, acuerdos y compromisos entre un Estado proactivo, Gobiernos Autónomos Descentralizados, entidades de apoyo de la Economía Popular y, Economía Popular y Solidaria (ONG), Universidades, entidades ligadas al desarrollo, entidades privadas y particularmente los actores de la Economía Popular y la Economía Popular y Solidaria.

En la AREPS se define a la Economía Popular y Solidaria como:

Conjunto de instituciones, recursos, y capacidades con los que los trabajadores y sus unidades domésticas en formas de organizaciones cooperativas, asociativas o comunitarias realizan las actividades de producción, distribución, circulación, financiamiento y consumo para generar bienes y servicios para el autoconsumo colectivo o intercambio en el mercado, y así generar ingresos para satisfacer necesidades individuales, familiares y organizativas, garantizando la producción y reproducción ampliada de la vida de todos sus integrantes (GRESP, 2010). 


\section{Ley Orgánica de Economía Popular Solidaria (LOEPS)}

La Ley Orgánica de Economía Popular y Solidaria aprobada el 13 de abril de 2011 y publicada en RO No. 444 de mayo 10 de 2011, busca dar un tratamiento diferenciado y referencial del Estado con los actores de la economía popular y solidaria.

Este cuerpo legal define el campo de acción de todos los actores de la economía popular y solidaria: las organizaciones del sector comunitario, asociativo y cooperativo; además exige el compromiso de los participantes para la profundización y cambio del modelo económico.

La normativa busca equiparar las condiciones productivas de la economía social y solidaria con la economía pública y la privada; facilita el acceso a los mercados así como garantiza que los integrantes de este sistema puedan competir en igualdad de condiciones con la empresa privada, permitiendo combatir la marginalidad y la pobreza y, sobre todo, la injusta distribución de la riqueza. Lo planteado proporciona mecanismos e incentivos a los ciudadanos ecuatorianos para poder realizar sus propuestas e ideas empresariales. (MIES-IEPS, 2011)

La Ley Orgánica de la Economía popular y Solidaria y del Sector Financiero Popular y Solidario, en su Artículo 1 define textualmente:

(...) Economía Popular y Solidaria forma de organización económica, donde sus integrantes, individual o colectivamente, organizan y desarrollan procesos de producción, intercambio, comercialización, financiamiento y consumo de bienes y servicios, para satisfacer necesidades y generar ingresos, basadas en relaciones de solidaridad, cooperación y reciprocidad, privilegiando al trabajo y al ser humano como sujeto y fin de su actividad, orientando al buen vivir, en armonía con la naturaleza por sobre la apropiación, el lucro y la acumulación de capital (Presidencia de la República, 2011). 
El ámbito definido en su Artículo 2, textualmente determina:

Se rigen por la presente Ley, todas las personas naturales y jurídicas, y demás formas de organización que, de acuerdo con la Constitución, conforman la economía popular y solidaria y el sector Financiero Popular y Solidario; y, las instituciones públicas encargadas de la rectoría, regulación, control, fortalecimiento, promoción y acompañamiento. (...) (Presidencia de la República, 2011).

La Ley distingue entre el sector productivo y financiero; en los siguientes cuadros se detallan las formas organizativas que corresponden a cada ámbito: 


\section{Cuadro 1}

\section{Formas de organización de la economía popular y solidaria: sector no financiero}

\begin{tabular}{|c|c|c|c|c|}
\hline \multicolumn{5}{|c|}{ Economía Popular y Solidaria (Sector No Financiero) } \\
\hline & \multicolumn{3}{|c|}{ Organizaciones del sector } & \multirow{2}{*}{$\begin{array}{l}\text { Unidades Eco- } \\
\text { nómicas Solida- } \\
\text { rias (UES) }\end{array}$} \\
\hline & Comunitario & Asociativo & Cooperativo & \\
\hline ڤี & $\begin{array}{l}\text { Conjunto de organiza- } \\
\text { ciones, vinculadas por } \\
\text { relaciones de territorio, } \\
\text { familiares, identidades } \\
\text { étnicas, culturales, de } \\
\text { género, de cuidado de la } \\
\text { naturaleza, urbanas; o de } \\
\text { comunas, comunidades } \\
\text { pueblos, su propósito es } \\
\text { la producción, comercia- } \\
\text { lización, distribución y el } \\
\text { consumo (bienes y servi- } \\
\text { cios), en forma solidaria } \\
\text { y autogestionada }\end{array}$ & $\begin{array}{l}\text { Conjunto de asocia- } \\
\text { ciones constituidas } \\
\text { por personas con ac- } \\
\text { tividades económicas } \\
\text { productivas similares } \\
\text { o complementarias; } \\
\text { para producir, comer- } \\
\text { cializar, y consumir } \\
\text { bienes y servicios; } \\
\text { en forma solidaria y } \\
\text { autogestionada }\end{array}$ & $\begin{array}{l}\text { Conjunto de coope- } \\
\text { rativas (sociedades } \\
\text { de personas) unidas } \\
\text { en forma volun- } \\
\text { taria, mediante } \\
\text { una empresa de } \\
\text { propiedad conjunta } \\
\text { y de gestión demo- } \\
\text { crática, con perso- } \\
\text { nería jurídica. }\end{array}$ & \multirow{3}{*}{$\begin{array}{l}\text { Las que se dedican } \\
\text { a las actividades } \\
\text { detalladas a } \\
\text { continuación. } \\
\text { Considera a los } \\
\text { ecuatorianos en } \\
\text { el exterior con sus } \\
\text { familiares en el } \\
\text { territorio nacional } \\
\text { y con los ecuato- } \\
\text { rianos retornados } \\
\text { e inmigrantes } \\
\text { extranjeros: La } \\
\text { economía del cui- } \\
\text { dado: Actividades } \\
\text { de reproducción y } \\
\text { sostenimiento de } \\
\text { la vida de las per- } \\
\text { sonas. Preparación } \\
\text { de alimentos, de } \\
\text { cuidado humano. } \\
\text { Personas naturales } \\
\text { los emprendi- } \\
\text { mientos uniperso- } \\
\text { nales, familiares. } \\
\text { Comerciantes } \\
\text { minoristas: Perso- } \\
\text { na natural, trabajo } \\
\text { autónomo, que no } \\
\text { supera los límites } \\
\text { de dependientes } \\
\text { asalariados... Ta- } \\
\text { lleres artesanales: } \\
\text { trabajador ma- } \\
\text { nual, maestro de } \\
\text { taller, autónomo. }\end{array}$} \\
\hline 营 & $\begin{array}{l}\text { Forma de gobierno que } \\
\text { mejor convenga a sus } \\
\text { costumbres, prácticas y } \\
\text { necesidades. Garantizan- } \\
\text { do su modelo de desarro- } \\
\text { llo económico endógeno, } \\
\text { desde su propia concep- } \\
\text { tualización y visión }\end{array}$ & $\begin{array}{l}\text { Cuenta con estatutos } \\
\text { (órgano de gobierno, } \\
\text { órgano directivo, } \\
\text { órgano de control } \\
\text { interno y administra- } \\
\text { ción). Su directiva es } \\
\text { elegida por mayoría } \\
\text { absoluta, sujetos a } \\
\text { rendición de cuentas, } \\
\text { alternabilidad y revo- } \\
\text { catoria de mandato. }\end{array}$ & $\begin{array}{l}\text { Contarán con: } \\
\text { Asamblea general } \\
\text { de socios, consejo } \\
\text { de administración, } \\
\text { consejo vigilante y } \\
\text { una gerencia }\end{array}$ & \\
\hline 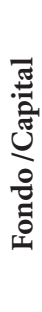 & $\begin{array}{l}\text { Fondo social variable } \\
\text { y constituido con los } \\
\text { fondos de sus miembros, } \\
\text { en numerario, trabajo o } \\
\text { bienes. Las donaciones, } \\
\text { aportes y contribucio- } \\
\text { nes no reembolsables } \\
\text { y legados de otras } \\
\text { organizaciones }\end{array}$ & $\begin{array}{l}\text { Capital social consti- } \\
\text { tuido por las cuotas } \\
\text { de admisión de sus } \\
\text { asociados, las ordina- } \\
\text { rias y extraordinarias, } \\
\text { que tienen el carácter } \\
\text { de no reembolsables, } \\
\text { y por excedentes del } \\
\text { ejercicio económico }\end{array}$ & $\begin{array}{l}\text { Capital social varia- } \\
\text { ble e ilimitado, se } \\
\text { constituye con las } \\
\text { aportaciones de so- } \\
\text { cios, en numerario, } \\
\text { bienes o trabajo. }\end{array}$ & \\
\hline
\end{tabular}

Fuente: LOEPS, 2011

Elaboración: Autora 


\section{Cuadro 2}

Formas de organización de la economía popular y solidaria: sector financiero

\begin{tabular}{|c|c|c|c|}
\hline \multicolumn{4}{|c|}{ Sector financiero popular y solidario } \\
\hline & $\begin{array}{l}\text { Cooperativas de } \\
\text { ahorro y crédito }\end{array}$ & $\begin{array}{l}\text { Entidades asociativas o } \\
\text { solidarias, cajas y ban- } \\
\text { cos comunales }\end{array}$ & Caja de Ahorros \\
\hline : & $\begin{array}{l}\text { Realizan actividades } \\
\text { de intermediación } \\
\text { financiera y de res- } \\
\text { ponsabilidad social } \\
\text { con sus socios y, } \\
\text { previa autorización de } \\
\text { la Superintendencia }\end{array}$ & $\begin{array}{l}\text { Realizan sus actividades } \\
\text { exclusivamente, en los } \\
\text { recintos, comunidades, } \\
\text { barrios o localidades en } \\
\text { donde se constituyen y se } \\
\text { pueden financiar, con sus } \\
\text { propios recursos o con } \\
\text { fondos provenientes de } \\
\text { programas o proyectos } \\
\text { ligados al desarrollo de sus } \\
\text { integrantes. Sus activida- } \\
\text { des se realizan en áreas de } \\
\text { influencia que no afecten } \\
\text { otras entidades financieras }\end{array}$ & $\begin{array}{l}\text { Instituciones integradas } \\
\text { por miembros de un mis- } \\
\text { mo gremio o institución; } \\
\text { por grupos de trabajado- } \\
\text { res con un empleador en } \\
\text { común, grupos familiares, } \\
\text { barriales; o por socios de } \\
\text { cooperativas distintas a las } \\
\text { de ahorro y crédito }\end{array}$ \\
\hline 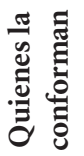 & $\begin{array}{l}\text { Formadas por per- } \\
\text { sonas naturales y } \\
\text { jurídicas que se unen } \\
\text { voluntariamente }\end{array}$ & \multicolumn{2}{|c|}{$\begin{array}{l}\text { Formadas por voluntad de sus socios y con aportes } \\
\text { económicos que, en calidad de ahorros sirven para el } \\
\text { otorgamiento de créditos a sus miembros, dentro de los } \\
\text { límites establecidos por la Superintendencia. }\end{array}$} \\
\hline
\end{tabular}

Fuente: LOEPS, 2011

Elaboración: Autora

Según datos de la Superintendencia de Economía Popular y Solidaria, en diciembre de 2013 se registraron 3330 cooperativas; de este total, 2384 son cooperativas no financieras, ${ }^{24} 946$ corresponden a las cooperativas de ahorro y crédito más una caja central. ${ }^{25}$ Con re-

24 La LOEPS en su Sección 3, las cooperativas de: producción, consumo, vivienda, servicios.

25 Art. 102.- Las Cajas Centrales, son instancias que se constituyen con, por lo menos, veinte cooperativas de ahorro y crédito (LOEPS, 2011), con 5977 169 socios (SEPS, 2017). 
lación a las asociaciones se registran 3 195, mismas que realizan actividades económicas no gremiales; en este sentido, se estima que en el Ecuador existen aproximadamente 12000 cajas y bancos comunales.

Del total de las cooperativas registradas, el 55\% corresponde a las cooperativas de servicios, el $28 \%$ a las cooperativas de ahorro y crédito, el 9\% a las cooperativas de producción, el 7\% a las de transporte y finalmente con un 0,3 a las de vivienda.

\section{De las instituciones gubernamentales de la EPS}

Varias son las instituciones creadas para asegurar la implementación de las políticas públicas referidas a la EPS. En el ámbito de la rectoría se encuentra el Comité Interinstitucional de la Economía Social, con su Consejo Consultivo; la regularización es ejercida por la Junta de Regularización; el control está a cargo de la Superintendencia de Economía Popular y Solidaria (SEPS); para el fomento y promoción el Instituto de Economía Popular y Solidaria (IEPS), adscrita al Ministerio de Inclusión Económica y Social (MIES); para brindar servicios financieros la Corporación Nacional de Finanzas Populares (CONAFIPS); y como entes de fortalecimiento financiero la Secretaría del Fondo de Liquidez y la Secretaría de Seguros de Depósitos.

\section{Rectoría: Comité Interinstitucional}

El Comité Institucional es la instancia de rectoría del sector. De conformidad con el Artículo 138 del Reglamento de la LOEPS el Comité Interinstitucional estará integrado por los Ministerios de Coordinación de Desarrollo Social (que lo presidirá); de la Producción y de Política Económica.

El Ministerio de Coordinación de Desarrollo Social es el encargado de elaborar, coordinar y concertar propuestas de políticas públicas para la Economía Popular y Solidaria y el Sector Financiero 
Popular y Solidario; como también de evaluar su cumplimiento e informar al comité para su aprobación.

El Comité Interinstitucional para el ejercicio de sus atribuciones contará con la información y opinión que le proporcione el Consejo Consultivo y con el apoyo del Instituto Nacional de Economía Popular y Solidaria.

La LOEPS en su Artículo 142 crea El Comité Interinstitucional como ente rector, cuya responsabilidad será la de:

(...) dictar y coordinar las políticas de fomento, promoción e incentivos, funcionamiento y control de las actividades económicas de las personas y organizaciones regidas por la ley, con el propósito de mejorarlas y fortalecerlas. Así mismo evaluará los resultados de la aplicación de las políticas de fomento, promoción e incentivos (Presidencia de la República, 2011).

Las atribuciones del Comité Interinstitucional están determinadas en el Artículo 138 del Reglamento General de la LOEPS; de acuerdo con el siguiente orden:

1. Dictar y coordinar las políticas de fomento, promoción, incentivos, funcionamiento y control de las actividades de las personas y organizaciones sujetas a la Ley.

2. Evaluar el cumplimiento de las políticas públicas.

3. Conocer y aprobar los informes de labores anuales de los entes de regulación.

4. Conocer la memoria anual del Superintendente.

5. Solicitar informes en cualquier momento a los organismos de regulación y de control.

6. Dictar política para la elaboración del Plan Nacional de Capacitación en Economía Popular y Solidaria (Superintendencia de Economía Popular y Solidaria, 2012). 


\section{Rectoría: Consejo consultivo}

La LOEPS en su Artículo 143, establece:

Los Gobiernos Autónomos Descentralizados, en el ámbito de sus competencias, las personas y organizaciones amparadas por esta Ley; podrán participar en la gestión del Comité Interinstitucional, a través de mecanismos de información y de consulta no vinculante (...) (Presidencia de la República, 2011).

Sus funciones están determinadas en el Artículo 143 del Reglamento General, de la LOEPS, de acuerdo con lo siguiente:

1. Brindar información sobre la situación del sector relacionado con la política a dictarse.

2. Emitir su opinión sobre los asuntos que le fueren requeridos por el Comité Interinstitucional.

3. Proponer recomendaciones sobre políticas y regulaciones orientadas a los sectores que representa (...) (Superintendencia de Economía Popular y Solidaria, 2012).

El Consejo Consultivo está integrado por nueve miembros: un representante de la Asociación de Municipalidades del Ecuador; un representante del Consorcio de Gobiernos Provinciales; un representante del Consejo Nacional de Gobiernos Parroquiales del Ecuador; un representante de las Federaciones de las Unidades Económicas Populares; tres representantes de las Federaciones de los sectores comunitarios, asociativos y cooperativista; y dos representantes del Sector Financiero Popular y Solidario. 


\section{Cuadro 3}

\section{Comité Interinstitucional de la Economía Solidaria}

\begin{tabular}{|c|c|c|}
\hline Ámbito & Comité Interinstitucional & Rol \\
\hline \multirow{3}{*}{ 苋 } & $\begin{array}{l}\text { Ministerio Coordinador de Desarrollo } \\
\text { Social (Preside) }\end{array}$ & \multirow{3}{*}{$\begin{array}{l}\text { Dictar, coordinar y evaluar las políti- } \\
\text { cas de fomento, promoción e incen- } \\
\text { tivos, funcionamiento y control de } \\
\text { las actividades económicas popular y } \\
\text { solidarias }\end{array}$} \\
\hline & $\begin{array}{l}\text { Ministerio Coordinador de Política } \\
\text { Económica }\end{array}$ & \\
\hline & $\begin{array}{l}\text { Ministerio de Producción, Empleo y } \\
\text { Competitividad }\end{array}$ & \\
\hline & Consejo Consultivo & \\
\hline \multirow{4}{*}{ 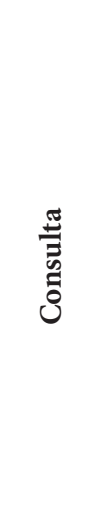 } & $\begin{array}{l}1 \text { Representante de la Asociación de } \\
\text { Municipalidades del Ecuador (AME) }\end{array}$ & \multirow{4}{*}{ Información y consulta no vinculante } \\
\hline & $\begin{array}{l}1 \text { Representante del Consorcio de } \\
\text { Gobiernos }\end{array}$ & \\
\hline & $\begin{array}{l}1 \text { Representante del Consejo Nacio- } \\
\text { nal de Gobiernos Parroquiales del } \\
\text { Ecuador }\end{array}$ & \\
\hline & $\begin{array}{l}6 \text { Representantes: } \\
\text {-1 Federación de las Unidades de } \\
\text { Economía Popular y Solidaria } \\
\text {-3 Federaciones de los sectores comu- } \\
\text { nitario asociativo cooperativista. } \\
\text { - } 2 \text { Sector Financiero Popular } \\
\text { Solidario }\end{array}$ & \\
\hline
\end{tabular}

Fuente: LOEPS, 2011

Elaboración: Autora

En el periodo 2012-2103, el Comité Interinstitucional establece como Política el "Precautelar la estabilidad, solidez, desarrollo y correcto funcionamiento de las instituciones de la Economía Popular y Solidaria y del Sector Financiero Popular y Solidario", 26 con lineamientos que en términos generales pretenden el fortalecimiento de una estructura organizacional naciente. Implementando procesos

26 Anexo 1: Políticas Públicas para la Economía Popular y Solidaria y del Sector Financiero Popular y Solidario s/f. 
formativos, sistemas de información, conectividad, entre otros. Las líneas de trabajo son:

- Fortalecer la institucionalidad pública creada por la LOEPS para la rectoría, regulación, control, fortalecimiento, promoción y acompañamiento de los actores de la EPS y del SFPS.

- Fortalecer a las organizaciones de la EPS y del SFPS, a través de procesos de educación formación, capacitación y fortalecimiento institucional y organizacional.

- Generar procesos de formación, educación y práctica en temas de asociatividad y economía solidaria.

- Diseñar e implementar un sistema integrado de información que permita la identificación, el seguimiento, el control y la investigación de este sector en todos los ámbitos.

- Fomentar el crecimiento ordenado del sector para el fortalecimiento integral del territorio.

- Vincular a los actores y organizaciones de la EPS y SFPS.

- Diseñar productos y servicios financieros diferenciados que permitan: la inclusión económica y social de los grupos excluidos del sistema financiero nacional, la innovación tecnológica, la agregación de valor, entre otros.

- Incorporar a las organizaciones del SFPS a la oferta de servicios disponibles.

- Fortalecer la conectividad entre las organizaciones de la EPS y del SFPS.

- Construir el Fondo de Liquidez y Seguro de Depósitos.

- Incorporar progresivamente al SFPS al Sistema Nacional de Pagos administrado por el Banco Central del Ecuador.

\section{Regulación: Junta de Regulación y MCDS (Secretaría técnica)}

El Artículo 144 de la Ley Orgánica de la Economía Popular y Solidaria y del Sector Financiero Popular y Solidario en concordan- 
cia con el Artículo 150 de su Reglamento, establece que la regulación de la Economía Popular y Solidaria será a través del Ministerio de Coordinación de Desarrollo Social; y la regulación del Sector Financiero Popular y Solidario estará a cargo de la Junta de Regulación, cuyas funciones están establecidas en el Artículo 149 del Reglamento de la Ley (Presidencia de la República, 2011).

\section{Cuadro 4}

Junta de Regulación

\begin{tabular}{|l|l|l|}
\hline Ámbito & \multicolumn{1}{|c|}{ Entidad } & \multicolumn{1}{|c|}{ Rol } \\
\hline & $\begin{array}{l}\text { Ministerio Coordinador de Desarrollo } \\
\text { Social } \\
\text { Junta de Regulación (Sector Financie- } \\
\text { ro, Popular y Solidario) } \\
\text { Secretaría Técnica de Economía Po- } \\
\text { pular y Solidaria }\end{array}$ & $\begin{array}{l}\text { Proponer regulaciones para la Eco- } \\
\text { nomía Popular y Solidaria y el Sector } \\
\text { Financiero Popular y Solidario. } \\
\text { Realizar seguimiento y eva- } \\
\text { luación del cumplimiento de } \\
\text { las regulaciones. } \\
\text { Generar información para la formu- } \\
\text { lación de políticas públicas por parte } \\
\text { del comité. }\end{array}$ \\
& & $\begin{array}{l}\text { Impulsar y coordinar la realización } \\
\text { de investigaciones o estudios sobre } \\
\text { diversos aspectos de la Economía } \\
\text { Popular y Solidaria y del Sector }\end{array}$ \\
& & $\begin{array}{l}\text { Financiero Popular y Solidario. } \\
\text { Brindar apoyo técnico y adminis- } \\
\text { trativo a los entes reguladores; y, las } \\
\text { demás que le sean asignadas por los } \\
\text { entes reguladores. }\end{array}$ \\
\hline
\end{tabular}

Fuente: LOEPS, 2011

Elaboración: Autora

De conformidad con el Artículo 145 del Reglamento de la Ley Orgánica de la Economía Popular y Solidaria y del Sector Financiero Popular y Solidario determina que:

La regulación es la capacidad de emitir la normativa necesaria para el adecuado cumplimiento de las políticas públicas expedidas por el Comité Interinstitucional con el fin de dirigir, orientar o modificar 
la conducta de las personas y organizaciones sujetas a la Ley. (...) (Presidencia de la República, 2011).

La Junta de Regulación estará presidida por el titular de coordinación de desarrollo social, y contará con una Secretaría Técnica a cargo de la presidencia. El Superintendente de Economía Popular y Solidaria y del Sector Financiero Popular y Solidario o su delegado, participarán en las sesiones de la Junta de Regulación en calidad de invitados con voz informativa pero sin voto.

\section{Control: Superintendencia de Economía Popular y Solidaria}

El control de la Economía Popular y Solidaria y del Sector Financiero Popular y Solidario está a cargo de la Superintendencia de Economía Popular y Solidaria, organismo técnico con jurisdicción nacional, personalidad jurídica de derecho público, patrimonio propio y autonomía administrativa y financiera; y con jurisdicción coactiva.

Para ejercer el control y la supervisión de las organizaciones, se desarrolló un modelo integral que considera las características específicas de las organizaciones de la economía popular y solidaria del Ecuador; y que incorpora la supervisión extra-situ, basada en los riegos específicos del sector y la supervisión in-situ.

Las atribuciones de la Superintendencia están determinadas en los Artículos 147 de la LOEPS y 154 de su Reglamento.

La Misión de la Superintendencia enfatiza en los principios y el campo de competencia de la institución y constituye un lineamiento motivador para mediante el trabajo y compromiso del talento humano, dar cumplimiento a su propósito:

Somos una entidad técnica de supervisión y control que busca el desarrollo, estabilidad, solidez y correcto funcionamiento del sector económico popular y solidario, con procesos técnicos, transparentes 
y confiables, para contribuir al bienestar de sus integrantes y de la comunidad en general. (Presidencia de la República, 2011)

La visión institucional determina el lineamiento de acción a largo plazo y es la expresión del estado futuro al que aspira llegar la Superintendencia; tomando en cuenta criterios objetivos y posibilidad de éxito.

\section{Cuadro 5}

Superintendencia de Economía Popular y Solidaria

\begin{tabular}{|c|l|l|}
\hline Ámbito & \multicolumn{1}{|c|}{ Entidad } & \multicolumn{1}{c|}{ Rol } \\
\hline & $\begin{array}{l}\text { Superintendencia de Economía } \\
\text { Popular y Solidaria (SEPS) }\end{array}$ & $\begin{array}{l}\text { Expedir normas de carácter general en las } \\
\text { materias de su competencia. Tiene jurisdic- } \\
\text { ción nacional } \\
\text { Anualmente debe presentar a la Asamblea, } \\
\text { una memoria de la labor realizada, así } \\
\text { como la situación económica de las institu- } \\
\text { ciones controladas. }\end{array}$ \\
\hline
\end{tabular}

Fuente: LOEPS, 2011

Elaboración: Autora

\section{Promoción: Instituto Nacional de Economía Populary Solidaria}

De conformidad con la LOEPS, el Instituto Nacional de Economía Popular y Solidaria es una entidad de derecho público adscrita al Ministerio a cargo de la inclusión económica y social, con jurisdicción nacional, dotado de personalidad jurídica, patrimonio propio y autonomía técnica, administrativa y financiera. Este órgano ejecuta la política pública, coordina, organiza y aplica de manera desconcentrada, los planes, programas y proyectos relacionados con los objetivos de la LOEPS.

Su misión es el fomento y promoción de las personas y organizaciones sujetas a la LOEPS, en el contexto del sistema económico social y solidario previsto en la Constitución de la República y consistente con el Plan Nacional de Desarrollo, con sujeción a las polí- 
ticas dictadas por el Comité Interinstitucional, para lo cual ejercerá las funciones de:

- Brindar apoyo y ejecutar las políticas públicas dictadas por el Comité Interinstitucional.

- Elaborar y ejecutar planes, programas y proyectos para el fortalecimiento organizativo y funcional de las entidades que forman parte de la Economía Popular y Solidaria.

- Ejecutar las medidas de fomento, promocione incentivos que correspondan en favor de las personas y organizaciones sujetas a la LOEPS, y verificar su cumplimiento.

- Promover y fomentar los circuitos de la Economía Popular y Solidaria.

- Generar y desarrollar estudios e investigaciones sobre la Economía Popular y Solidaria.

- Promover y formar capacitadores para las organizaciones de la Economía Popular y Solidaria.

- Coordinar la ejecución de sus funciones con las diferentes instituciones del Estado, Organizaciones de la sociedad civil y de la comunidad en general.

- Proponer políticas públicas para el desarrollo de la economía popular y solidaria, los sectores, organizaciones y personas que lo conforman.

- Estimular y coordinar la cooperación entre las instituciones del Estado, gobiernos autónomos descentralizados, organizaciones de la sociedad civil y de la comunidad en general, en acciones y programa dirigidos al desarrollo y fomento de la economía popular y solidaria.

- Diseñar e implementar estrategias de inserción y participación de las personas y organizaciones de la economía popular y solidaria en los mercados público y privado, propiciando relaciones directas entre productores y consumidores (Superintendencia de Economía Popular y Solidaria, 2012). 


\title{
Financiamiento: Corporación nacional de finanzas populares $y$ solidarias (Fondo de liquidez y seguro de depósitos)
}

\author{
Cuadro 6 \\ Entidades de fomento: Instituto Nacional de Economía Popular \\ y Solidaria/Corporación Nacional de Finanzas Populares Y Solidaria
}

\begin{tabular}{|c|c|c|}
\hline Ámbito & Entidad & Rol \\
\hline \multirow{3}{*}{$\begin{array}{l}\stackrel{0}{\Xi} \\
\text { : } \\
\text { : }\end{array}$} & $\begin{array}{l}\text { Instituto Nacional de Economía Popular y } \\
\text { Solidaria (IEPS) }\end{array}$ & $\begin{array}{l}\text { Ejecuta la política pública, coor- } \\
\text { dina, organiza y aplica de ma- } \\
\text { nera desconcentrada, los planes, } \\
\text { programas y proyectos. } \\
\text { Entidad Adscrita al Ministerio } \\
\text { de Economía Social y Solidaria } \\
\text { (MIES) }\end{array}$ \\
\hline & $\begin{array}{l}\text { Corporación Nacional de Finanzas Popula- } \\
\text { res y Solidarias }\end{array}$ & $\begin{array}{l}\text { Brindar servicios financieros y } \\
\text { crediticios de segundo piso. } \\
\text { Está bajo el control de la Super- } \\
\text { intendencia de Economía Popu- } \\
\text { lar y Solidaria y debe observar } \\
\text { las disposiciones del Código } \\
\text { Orgánico de Planificación y } \\
\text { Finanzas Públicas. }\end{array}$ \\
\hline & $\begin{array}{l}\text { Banco Central/Secretaría Técnica/ } \\
\text { Fondo de liquidez } \\
\text { Corporación de Seguros de Depósito } \\
\text { (COSEDE)/Secretaría Técnica/Segu- } \\
\text { ro de Depósitos } \\
\text { Directorio Único: } \\
\text { Ministerio Coordinador de Desarrollo } \\
\text { Social (Preside) } \\
\text { Ministerio Coordinador de la Política } \\
\text { Económica } \\
1 \text { Delegado del Comité Interinstitucional } \\
1 \text { Técnico delegado por el Directorio de la } \\
\text { CONAFIPS }\end{array}$ & \\
\hline
\end{tabular}

Fuente: LOEPS, 2011

Elaboración: Autora

La Corporación Nacional de Finanzas Populares y Solidarias es un organismo de derecho público, dotado de personalidad jurídi- 
ca, patrimonio propio y autonomía administrativa, técnica y financiera, con jurisdicción nacional. Su misión fundamental es brindar servicio financieros con sujeción a la política dictada por el Comité Interinstitucional a las organizaciones amparadas por la LOEPS, bajo mecanismos de servicios financieros y crediticios de segundo piso; para lo cual ejercerá las funciones que constarán en su Estatuto social. La Corporación aplicará las normas de solvencia y prudencia financiera que dicte la Superintendencia con el propósito de preservar de manera permanente su solvencia patrimonial.

De conformidad con la Ley Orgánica de Economía Popular y Solidaria y del Sector Financiero Popular y Solidario se crean el Fondo de Liquidez y el Seguro de Depósitos del Sector Financiero Popular y Solidario como mecanismos articulados y complementarios; con el objeto de conceder créditos de liquidez, de liquidez contingente y para cubrir deficiencias en la cámara de compensación a las cooperativas de ahorro y crédito, entidades asociativas o solidarias, cajas y bancos comunales y en las cajas de ahorro, reguladas por esta ley; así como para proteger los depósitos efectuados.

Estos mecanismos operan a través de fideicomisos mercantiles de inversión, que serán controlados exclusivamente por la Superintendencia y administrados por la Secretaría Técnica.

El Artículo 3, establece el objeto de la Ley de conformidad con lo siguiente:

a. Reconocer, fomentar y fortalecer la Economía Popular y Solidaria y el Sector Financiero Popular y Solidario en su ejercicio relación con los demás sectores de la economía y con el Estado;

b. Potenciar las prácticas de la economía popular y solidaria que se desarrollan en las comunas, comunidades, pueblos y nacionalidades y en sus unidades económicas productivas para alcanzar el Sumak Kawsay; 
c. Establecer un marco jurídico común para las personas naturales y jurídicas que integran la Economía popular y Solidaria; y, del Sector Financiero Popular y Solidario.

d. Instituir el régimen de derechos, obligaciones y beneficios de las personas y organizaciones sujetas a esta Ley; y,

e. Establecer la institucionalidad publica que ejercerá la rectoría, regulación, control, fomento y acompañamiento (Presidencia de la República, 2011).

Por último, es necesario destacar lo que estipula la Ley para las personas y organizaciones amparadas por la LOEPS, quienes de conformidad con el Artículo 4 se guiarán por los siguientes principios:

a. La búsqueda del buen vivir y del bien común;

b. La prelación del trabajo sobre el capital y de los intereses colectivos sobre los individuales;

c. El comercio justo y consumo ético y responsable;

d. La equidad de género;

e. El respeto a la identidad cultural;

f. La autogestión;

g. La responsabilidad social y ambiental, la solidaridad y rendición de cuentas: $y$,

h. La distribución equitativa y solidaria de excedentes (Presidencia de la República, 2011). 